\title{
Developing an Algorithm for Selecting Experts That Determine Technical Characteristics of Technological Equipment
}

\author{
A.N. Feofanov ${ }^{1, *}$ and A.G. Busheva ${ }^{2}$ \\ ${ }^{1}$ MSTU "STANKIN", Department of Engineering Graphics, 127055 Moscow Vadkovsky lane, 1, \\ Russia \\ ${ }^{2}$ MSTU "STANKIN", Department of Automated Information Processing and Control Systems, \\ 127055 Moscow Vadkovsky lane, 1, Russia
}

\begin{abstract}
This article discusses the main ways of selecting candidates for expert groups. The qualities necessary for an expert are indicated. Questionnaires have been developed, the answers to which will help to form a database of candidates. An algorithm is presented, with the help of which experts are selected according to given conditions.
\end{abstract}

\section{Introduction}

Nowadays a lot of attention is paid to the quality of products worldwide. Quality, as well as competitiveness, directly depends on managerial decisions taken at all stages of the product life cycle. Following the transition to a post-industrial society, when it comes to processes, theoretical knowledge is of key value to humanity.

The most common type of equipment in metalworking technological equipment is a drilling jig. A jig is a device designed for basing a workpiece and processing it without prior markings. It allows you to correctly position the drill and the workpiece to improve machining accuracy. [1]

The accuracy of manufacturing a product on a drilling machine largely depends on the direction of the drill. The jig bushings used in the mentioned equipment are designed to ensure the direction of the cutting tool and reduce its deflection in order to achieve the required accuracy of the machined holes: their diametric dimensions, shapes and the position of the axes. [2] To ensure the required accuracy of the hole being machined, drilling jigs with various types of bushings are used: permanent, replaceable, quick-change and special. Deciding which bushings to use depends on the production technology of a particular product.

An expert assessment can dictate the use of certain devices and increase the accuracy of products at the stage of developing a technological map and choosing equipment. This will significantly reduce the financial losses of an enterprise.

The method of group examination is being increasingly used to obtain an objective assessment in the tasks of qualimetry, forecasting, business management, etc. [3] Adopting

\footnotetext{
*Corresponding author: zub97@mail.ru
} 
a particular management decision may directly depend on the analysis of the expert group, which is why it is necessary to approach its formation carefully.

\section{Expert groups}

\subsection{Methods for selecting candidates for expert groups}

In order to organize the assessment, it is necessary to form an expert group. It is convenient to select candidates according to a certain algorithm in order to assess how well they fit the criteria.

There are a huge number of methods for selecting experts: documentary, experimental, mutual assessment and self-assessment of the degree of competence and objectivity. None of these methods can provide a $100 \%$ guarantee that the chosen solution will be correct. [3, 4]

When selecting experts, it is proposed to use these methods in combination, which will allow to select the most competent specialist.

The number of participants in the examination should not exceed 28 participants. Research [5] has shown that the value of the mean group error when the number of experts is more than 28 is insignificant.

\subsection{The main qualities of an expert}

A candidate for an expert group should have the following qualities:

1. Awareness - experience in a given subject area.

2. Ingenuity - the ability to find non-standard solutions.

3. Anti-conformism - not being dependent on the opinions of the authority figures.

4. Communality - possessing teamwork skills.

5. Practicality - creating solutions that can be applied in practice at the lowest cost without compromising quality.

6. Interest - the desire to work on solving problems. [6]

It is the assessment of these qualities that is the most difficult task when selecting specialists for the group. Most of the above indicators are qualitative, therefore they cannot be assessed on a single scale, which in turn most often leads to errors.

The group examination method can be applied in all areas of producing and providing services. Any business or organization can use it to increase profits and efficiency. Creating an automated system will help to select experts with minimal resource costs, thereby increasing the availability of group expertise for the customer.

\section{An automated decision support system}

\subsection{The main characteristics of a system that automatically selects experts}

The first step in creating the system is developing an algorithm that will check whether the experts fit the given criteria (conditions).

The decision support system (DSS) has a cooperative form. This allows the user to tweak decisions made by the system in manual mode to provide double control. It is proposed to use a three-tier data warehouse when creating and adding data marts in order to save time. [7] 
The work of BV Boytsov, G.S. Zhetesova and M.K. Ibatov "Architecture of the analytical system for assessing educational programs of groups" describes the main features of the architecture of the analytical system for assessing educational programs, presents the process of developing a multi-component mathematical model for assessing professional competencies of students. [8]

This system ensures the storage, processing and analysis of data. The method of assessing the competence of students has a lot in common with the method of assessing experts. For example, the level of education and area of expertise are also taken into account. [8]

The information is stored in a database (DB). Information processing and analysis is achieved by using special tools for loading, transforming, and analyzing mass data. [8]

Since the structure of the system is based on the analysis of a large amount of data, it ensures high efficiency in solving production problems.

\subsection{Factors influencing the choice of an expert}

Further in the paper tables will be presented, including answers from experts and data received from the personnel department (documentary method). A coefficient is proposed for each criterion, which is supposed to demonstrate the significance of the factor. A criterion is an objective indicator of the assessed parameter, which is created by analyzing the presented result. [8]

The coefficients used for the selection of experts provide an opportunity to select a specialist who is well versed in a given subject area. In our case, it is the work of drilling equipment.

The first and most important factor is the presence or absence of the expert's desire to participate in the examination. If the expert's answer is "no", then considering his further parameters is not sensible. A sample form is shown in Table 1.

Table 1. Does the expert want to take part?

\begin{tabular}{|c|c|c|}
\hline The expert's answer & Yes & No \\
\hline Points (i) & 1 & 0 \\
\hline
\end{tabular}

The second factor is knowing the principles of how drilling equipment operates. Experts who are not familiar with the way this equipment operates will not be considered. A sample form is shown in Table 2.

Table 2. Knowing the principles of how drilling equipment operates

\begin{tabular}{|c|c|c|c|c|c|}
\hline Involvement & $\begin{array}{c}\text { Not } \\
\text { familiar }\end{array}$ & $\begin{array}{c}\text { Has } \\
\text { theoretical } \\
\text { knowledge } \\
\text { in this area }\end{array}$ & $\begin{array}{c}\text { Worked } \\
\text { with such } \\
\text { equipment }\end{array}$ & $\begin{array}{c}\text { Participated in developing the } \\
\text { technologies for the production } \\
\text { of products on drilling } \\
\text { equipment }\end{array}$ & $\begin{array}{c}\text { Has a } \\
\text { patent in } \\
\text { this area }\end{array}$ \\
\hline Points (a) & 0 & 1 & 3 & 5 & 10 \\
\hline
\end{tabular}

An employee's seniority speaks of their work experience and skills acquired on the job or as a result of scientific work. Since this indicator is quite important, its coefficient is 1.5. A sample form is shown in Table 3.

Table 3. Work experience

\begin{tabular}{|c|c|c|c|c|}
\hline Years & $0-3$ & $4-9$ & $10-19$ & $>20$ \\
\hline Points (b) & 1 & 2 & 3 & 4 \\
\hline
\end{tabular}


Education level is just as important as work experience, as it indicates the candidate's theoretical knowledge. The coefficient is 1.5. A sample form is shown in Table 4.

Table 4. Education

\begin{tabular}{|c|c|c|c|c|c|c|}
\hline $\begin{array}{c}\text { Education } \\
\text { level }\end{array}$ & Secondary & $\begin{array}{c}\text { TVET } \\
\text { (Technical and } \\
\text { Vocational } \\
\text { Education and } \\
\text { Training) }\end{array}$ & $\begin{array}{c}\text { Bachelor's } \\
\text { degree }\end{array}$ & $\begin{array}{c}\text { Master's } \\
\text { degree }\end{array}$ & $\begin{array}{c}\text { Candidate } \\
\text { of } \\
\text { Sciences }\end{array}$ & $\begin{array}{c}\text { Doctor of } \\
\text { Sciences (two } \\
\text { doctoral level } \\
\text { scientific } \\
\text { degrees) }\end{array}$ \\
\hline Points (c) & 1 & 2 & 3 & 4 & 5 & 6 \\
\hline
\end{tabular}

It is easy enough to calculate the number of papers done by a candidate, but it is impossible to assess the quality of the carried-out research, therefore the coefficient of this parameter is 1.25. A sample form is shown in Table 5.

Table 5. Number of scientific papers

\begin{tabular}{|c|c|c|c|c|}
\hline Number & $0-9$ & $10-39$ & $40-79$ & $>80$ \\
\hline Points (d) & 1 & 2 & 3 & 4 \\
\hline
\end{tabular}

The Hirsch index is a quantitative characteristic of a scientist's productivity based on the number of their publications and the number of citations of these publications. A sample form is shown in Table 6.

Table 6. Hirsch index

\begin{tabular}{|c|c|c|c|c|}
\hline Index & $0-2$ & $3-6$ & $7-10$ & $>10$ \\
\hline Points (e) & 1 & 2 & 3 & 4 \\
\hline
\end{tabular}

The number of examinations performed is the most important factor in our case. Candidates with experience in this area are valued more because for them the expertise is not a stressful situation, they are familiar with all the rules, therefore the probability of getting a subjective assessment is much higher. The coefficient is 2 . A sample form is presented in table 7 .

Table 7. The number of examinations performed

\begin{tabular}{|c|c|c|c|c|}
\hline Number & $0-3$ & $4-9$ & $10-29$ & $>30$ \\
\hline Points (f) & 1 & 2 & 3 & 4 \\
\hline
\end{tabular}

\subsection{Factors influencing the choice of an expert}

A specialist wishing to participate in the examination receives a form consisting of tables 2 , $5,6,7$ via e-mail. When answering the questions, it is necessary to provide links to scientific papers (if there are any) and documents confirming participation in previous examinations.

Next, a request is sent to the HR department to obtain the information required for tables 3 and 4 .

After that, the candidate's data is stored in the database, and in the event of a need to form an expert group, the candidate will need to indicate their desire to participate.

Figure 1 shows an algorithm for selecting experts. The data of each expert available in the database "goes" through the algorithm, after which a coefficient $\mathrm{k}$ is assigned to each candidate. After analyzing the questionnaires of all participants, a list of candidates is 
formed. The higher the value of the coefficient $k$, the higher the degree of the candidate's suitability for participating in expert assessment.

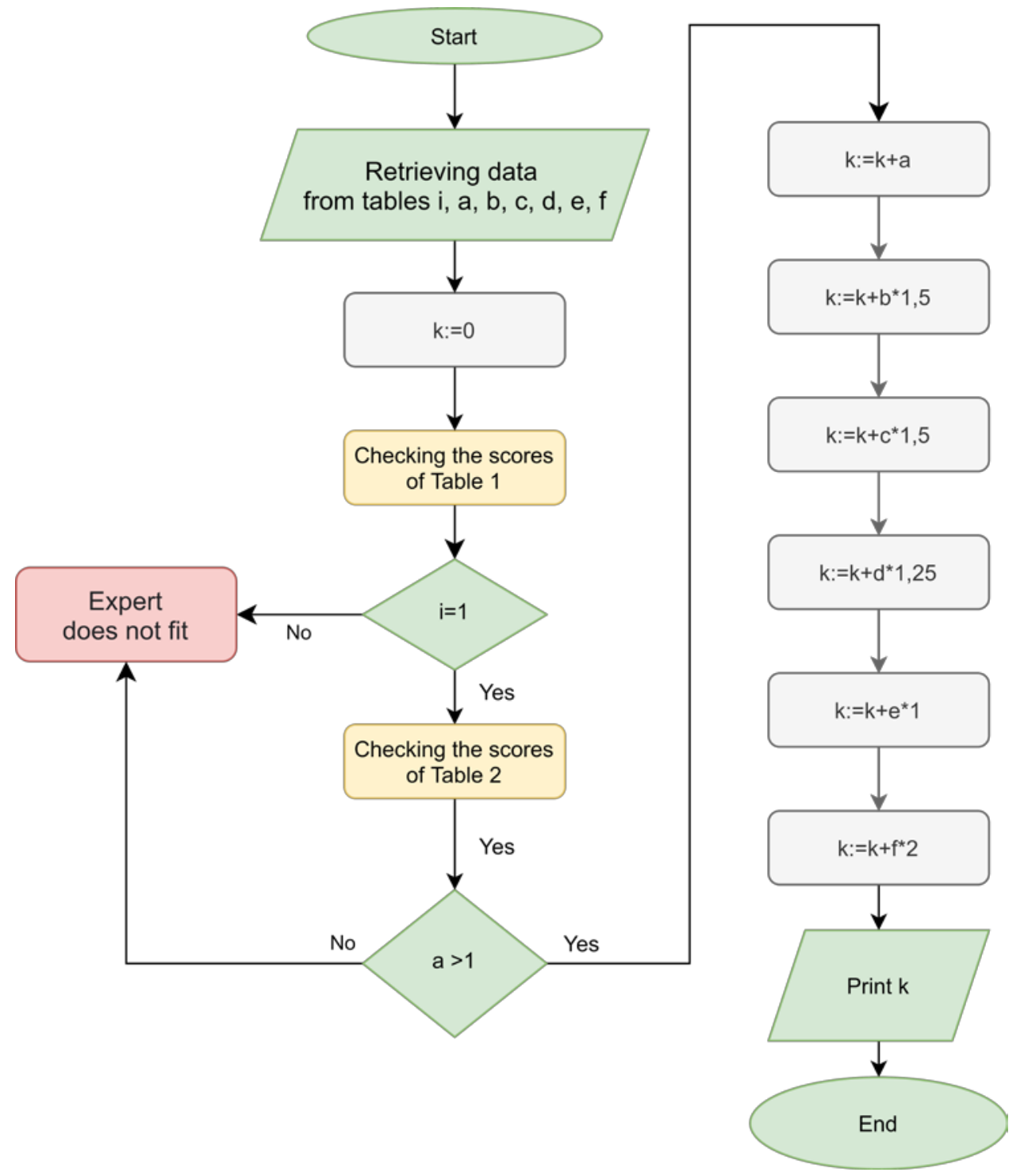

Fig. 1. Expert selection algorithm

\section{Conclusions}

The use of the algorithm makes it possible to automate the selection of experts in the future using the DSS. This will save significant time and other important resources that usually pose a problem when working with large amounts of data. Using DSS will significantly reduce the number of errors arising from manual selection, as well as reduce the impact of the human factor. 


\section{References}

1. I.V. Levinsky, Pneumatic tools and devices in mechanical engineering (Mashgiz, Kiev, 1954)

2. A. A. Gusev, I. A. Guseva, Design of technological equipment: a textbook for university students (Mashinostroyeniye, Moscow, 2013)

3. R.M. Khvastunov, A.N. Feofanov, V.M. Korneeva, E.G. Nahapetyan, Qualimetry in mechanical engineering. Series: Textbook for universities (Ekzamen, Moscow, 2009)

4. R.M. Khvastunov, N.P. Negrimovskaya, A.N. Feofanov, Methods for selecting specialists for expert groups, Engineering technology, v. 10, pp. 58-67 (2008)

5. N.C. Dalkey, The Delphi Method: An Experimental Study of Group Opinion. Rand Memorandum (The Rand Corporation, Santa Monica, CA, 1969)

6. Y.F. Martemyanov, T. Y. Lazareva, Expert Decision Making Techniques: A Study Guide (Tambov State Technical University Publishing House, Tambov, 2010)

7. A.G. Busheva, A.N. Feofanov, Development of an algorithm for an automated system for selecting an expert for corrective measures to improve the characteristics of the drilling jig, Automation and simulation in design and control, v. 1(11), pp. 52-61 (2021)

8. B. V. Boytsov, G. S. Zhetesova, M. K. Ibatov, The architecture of the analytical system for evaluating educational programs of groups, Quality and life, v.2, pp. 24-28 (2018) 